\title{
UTILIZAÇÃO DE ENXERTO AUTÓGENO DE CRISTA ILÍACA PARA A RECONSTRUÇÃO DE MAXILA ATRÓFICA
}

Paola CORSO, Fabiano GALINA, Paulo MULLER, Rafaela SCARIOT, Delson COSTA

A manutenção do volume ósseo se dispõe de total importância em se tratando de reabilitação de maxila atrófica para restabelecer a função do sistema estomatognático com implantes dentários. Segundo LEKHOLM et al., 1999, a área doadora escolhida com maior freqüência para a reconstrução de grandes defeitos em rebordos maxilares e mandibulares é o osso ilíaco, por suas características morfológicas, estruturais e grande quantidade de osso esponjoso medular, alem de uma significativa quantidade de cortical óssea. Paciente E.L.S.P., gênero feminino, 48 anos, procurou o servido de Cirurgia e Traumatologia Buco-Maxilo-Facial da Universidade Federal do Paraná apresentando ausência total de dentes em maxila. Sua queixa principal era a dificuldade mastigatória. O plano de tratamento proposto foi uma reabilitação com osso ilíaco para posterior instalação de oito implantes dentários. Durante a cirurgia de enxertia óssea foi realizado levantamento de seio maxilar bilateral, com osso cortico-medular particularizado, e fixação de quatro blocos adaptados na região anterior de maxila. A tomografia computadorizada pósoperatória confirmou grande quantidade óssea na região proposta para reabilitação.

Palavras-chave: Reabilitação; llíaco; Enxerto; Maxila 